Correspondence: D McLeod,

Tel: +44161276 5645;

Fax: + 441612736354

E-mail: david.mcleod@man.ac.uk

Eye (2005) 19, 1350-1351. doi:10.1038/sj.eye.6701795; published online 28 January 2005

Sir,

\section{Reply to McLeod}

We would like to thank to Dr. McLeod for his constructive contributions to our paper describing retinal vascular occlusions in two cases with homocystinaemia. ${ }^{1}$ In our paper, we have primarily focused on the finding of homocystinaemia as a cause of vascular occlusions in young patients; however, we have not discussed the probable mechanisms of association of arterial and venous obstructive disease. Three different clinical syndromes have been suggested describing simultaneous arterial and venous obstructions of the retina including; the combination of central retinal artery and vein obstruction; combined occlusion of central retinal vein and cilioretinal artery; and combined branch retinal artery and central retinal vein obstruction. ${ }^{2}$ We agree with Dr McLeod in that the arterial obstruction may actually be a relative hypoperfusion of the cilioretinal arteries secondary to increased retinal venous pressure. ${ }^{3,4}$ Although this dependent occlusion is the most probable explanation, therapeutic lowering of the intraocular pressure was attempted in the presented case considering the other possibilities like two simultaneous (but separate) occlusions which may be the case in a patient with homocystinaemia.

\section{References}

1 Ozdek S, Yulek F, Gurelik G, Aydin B, Hasanreisoglu B. Simultaneous central retinal vein and retinal artery branch occlusions in two patients with homocystinaemia. Eye 2004; 18: $942-945$.

2 Singh AJ. Branch retinal artery obstruction with simultaneous central retinal vein occlusion. Eye 2001; 15: 225-227.

3 McLeod D, Ring CP. Cilio-retinal infarction after retinal vein occlusion. Br J Ophthalmol 1976; 60: 419-427.

4 McLeod D. Central retinal vein obstruction with cilio-retinal infarction. Eye 2003; 17: 283.

S Ozdek

Ophthalmology Department, School of Medicine, Gazi University, Ankara, Turkey

Correspondence: S Ozdek, Isci Blokları mah. 31. Cad., Ozgur Anıl sit. A-Blok No: 30, 100.YIL
06530, Ankara, Turkey

Tel/Fax: + 903122125794

E-mail: sozdek@gazi.edu.tr

Eye (2005) 19, 1351. doi:10.1038/sj.eye.6701796; published online 21 January 2005

Sir,

Diode laser trans-scleral cyclophotocoagulation in the management of glaucoma in patients with long-term intravitreal silicone oil

We read with great interest the article by Sivagnanavel et al. ${ }^{1}$ We will be most grateful if the authors can help to clarify a few points.

In this series, the authors described a significant number of subjects losing vision after trans-scleral cyclophotocoagulation (TSCPC). They felt that the loss was not quantifiable because of the poor visual acuity. They concluded that TSCPC failed to protect against visual loss in the long term. We may like to be aware that it is the natural course of their disease to lose vision. Hence, they may like to compare with the rate of visual loss in the TSCPC-treated group with a control group having similar glaucoma associated with long-term silicone oil placement, and who were treated with other modalities. It may be of interest for the authors to attempt quantification with Logmar (Logarithm of Minimum Angle of Resolution) chart, or express the percentage of eyes losing 2 or more lines.

If the eight cases of ocular comorbidity were excluded, the success rate can actually be raised to $50 \%$. As the authors rightly pointed out, the prolonged placement of silicone oil before treatment (mean duration of oil before TSCPC was 33.7 months (range 1-113 months, $\mathrm{SD}=26.9)$ ), and prolonged duration before successfully bringing down the IOP ( $53 \%$ of the patients took 450 days to reduce the IOP to below $21 \mathrm{mmHg}$ ), might be factors contributing to the low overall success rate. We may like to be aware of the fact that the success and failure definitions were slightly different among different studies so that the rates may not be accurately comparable with each other. ${ }^{2}$

The authors did possess evidence in support of the efficacy of the TSCPC: the average number of IOP-lowering medications prior to TSCPC was 2.6 (range 1-5). This was reduced to 1.0 (range 0-3) following TSCPC at final follow-up. Moreover, the authors regarded the procedure to be very safe with few side effects. At the time of writing, as far as we know, there is an absence of strong data in the literature supporting other modalities of treatment in the same 
situation, especially when significant proliferative vitreoretinopathy precludes safe removal of silicone oil. Therefore, despite its shortcomings, TSCPC may still be regarded as one of the most efficacious and feasible armamentarium presently available.

We commend the authors for their valuable work on this issue, and hope that our suggestions would broaden the discussion.

\section{Acknowledgements}

Financial or proprietary interest: Nil Financial support: Nil

\section{References}

1 Sivagnanavel V, Ortiz-Hurtado A, Williamson TH. Diode laser trans-scleral cyclophotocoagulation in the management of glaucoma in patients with long-term intravitreal silicone oil. Eye 2004 Jul 23 [Epub ahead of print].

2 Han SK, Park KH, Kim DM, Chang BL. Effect of diode laser trans-scleral cyclophotocoagulation in the management of glaucoma after intravitreal silicone oil injection for complicated retinal detachments. Br J Ophthalmol 1999; 83(6); 713-717.

\section{DYL Leung and DSC Lam}

Department of Ophthalmology \& Visual Sciences, The Chinese University of Hong Kong, 3/F., Hong Kong Eye Hospital, 147K Argyle Street, Kowloon, Hong Kong, People's Republic of China

Correspondence: DSC Lam,

Tel: + 8522762 3157;

Fax: + 85227159490 .

E-mail: dennislam@cuhk.edu.hk

Eye (2005) 19, 1351-1352. doi:10.1038/sj.eye.6701790; published online 24 December 2004

\section{Sir,}

\section{Reply to DYL Leung and DSC Lam}

We are grateful for the comments on our recent article. The correspondents claim that the conditions that we have treated would have lost vision in time due to their natural history, but we cannot entirely agree that this is the case with exception perhaps of diabetic retinopathy, which comprised only one patient in our study. We do, however, agree that any other modalities to control the intraocular pressure are also likely to have fared badly. The response of our unit to the poor results of diode laser trans-scleral cryophotocoagulation (TSCPC) has been to try to remove silicone in all cases, where possible, early in the management of the condition. Of course, a risk of retinal redetachment is then encountered. ${ }^{1}$ This risk we feel is justified given the high incidence of silicone oilinduced glaucoma ${ }^{2}$ and the poor results of control of the glaucoma thereafter emphasized from the results of our study. We are now using TSCPC only rarely when all other options have been ruled out.

\section{References}

1 Casswell AG, Gregor ZJ. Silicone oil removal: II. Operative and postoperative complications. Br J Ophthalmol 1987; 71: 898-902.

2 Barr CC, Lai MY, Lean JS, Linton KLP, Trese M, Abrams G et al. The Silicone Study Group. Postoperative intraocular pressure abnormalities in the silicone study. Ophthalmology 1993; 100: 1629-1635.

TH Williamson ${ }^{1}$ and $V$ Sivagnanavel ${ }^{2}$

${ }^{1}$ Department Of Ophthalmology,

St. Thomas' Hospital, Lambeth Palace Road, Westminster, London SE1 7EH,

UK

${ }^{2}$ Department of Ophthalmology,

Kings College Hospital,

Denmark Hill

Correspondence: TH Williamson,

Tel: +44 2071887188 ;

Fax: + 442079288157.

E-mail: tom@retinasurgery.co.uk

Eye (2005) 19, 1352. doi:10.1038/sj.eye.6701791; published online 24 December 2004 